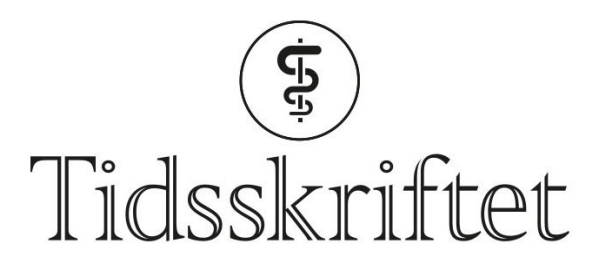

DEN NORSKE LEGEFORENING

\title{
Nevrokulturell imperialisme
}

ESSAY

\section{PER BRODAL}

E-post: pabrodal@gmail.com

Per Brodal er professor emeritus i medisin (anatomi) ved Institutt for medisinske basalfag, Universitetet i Oslo, med spesialkompetanse innen nevrobiologi og medisinsk utdanning. Forfatter har fylt ut ICMJE-skjemaet og oppgir ingen interessekonflikter.

Hjerneforskning har høy prestisje, men kritiske røster hevder at resultatene blir oversolgt. Gir forskerne løfter om å forklare fenomener hjerneforskning egentlig ikke kan gi svar på?

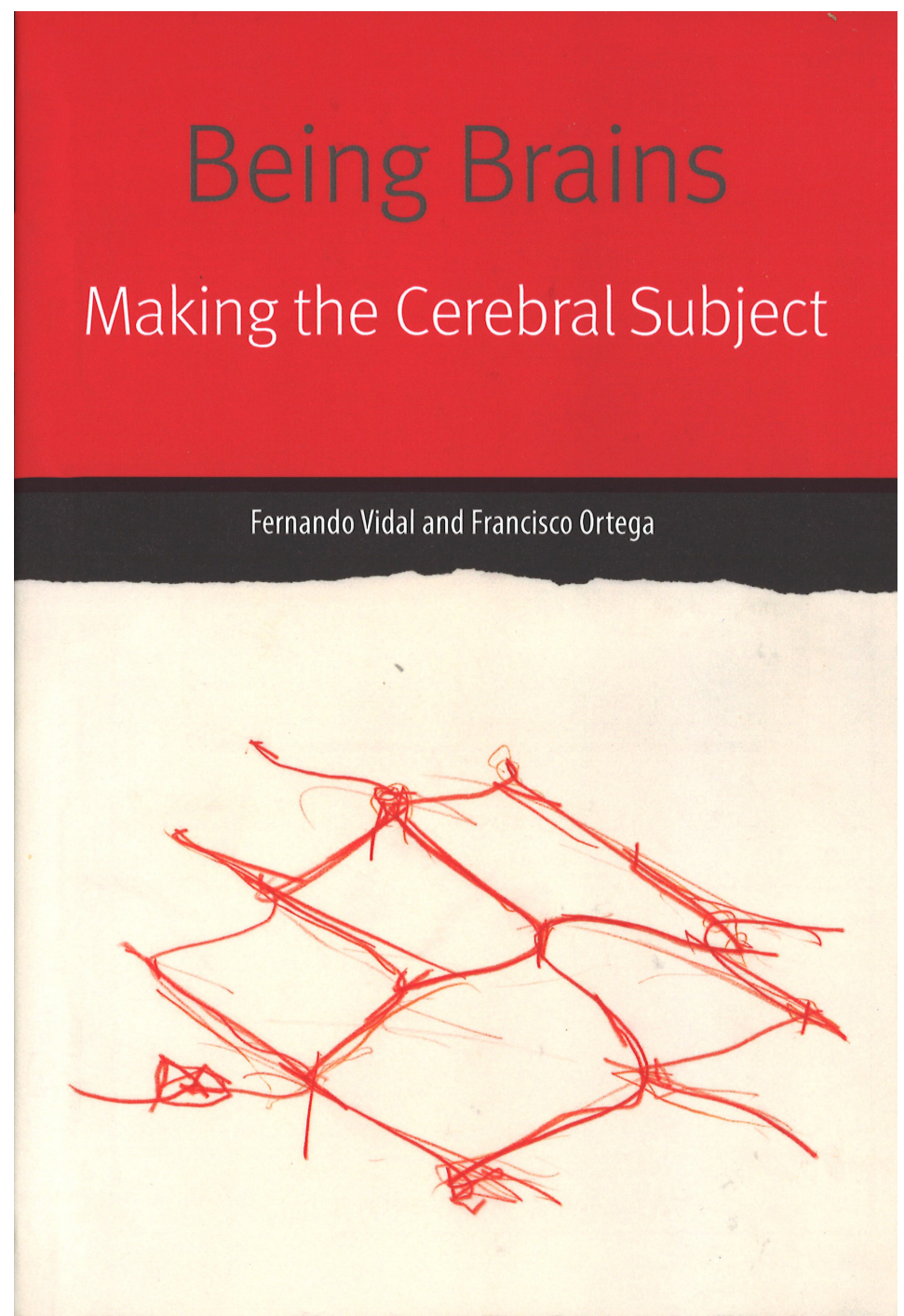

Aktuell bok. Fernando Vidal og Francisco Ortega. Being Brains. Making the Cerebral Subject. New 
Gjennom et langt yrkesliv med eksperimentell hjerneforskning er jeg blitt økende skeptisk til hvordan mange hjerneforskere forstår sitt eget felt og formidler sine resultater til allmennheten. Jeg husker ennå inntrykket det gjorde da jeg i 1992 leste en lederartikkel i første nummer av tidsskriftet Consciousness and Cognition hvor David Galin fra University of California skrev følgende: «... in my youth I had been led astray by hard sell and high social standing of naive reductionism» (1). Det satte ord på mitt eget gryende ubehag ved det jeg opplevde som ukritisk reduksjonisme blant mange - også ledende - hjerneforskere. Med naiv i denne sammenhengen mente Galin at forskerne ikke så begrensningene i sine forklaringsmodeller og derfor trakk alt for vide slutninger fra sine forskningsresultater. «Ondartete reduksjonister» kalte ham dem som ikke bare overtolket sine funn, men også mente at delene var mer virkelige enn helheten, og at jo mindre delene var, jo virkeligere var de.

\section{Overselges hjerneforskningen?}

Hjerneforskning har enda høyere prestisje nå enn i 1992 og tiltrekker seg enorme forskningsmidler gjennom satsinger som USAs BRAIN Initiative, EUs Human Brain Project og private donasjoner. Likevel er det åpenbart ikke nok: I en artikkel i Science i 2014 slås det for eksempel fast at økte bevilgninger til hjerneforskning er en moralsk forpliktelse hvis vi $\emptyset n s k e r$ å ta psykiske lidelser blant ungdom på alvor (2). Dette var ikke en enslig røst, men basert på et prestisjefylt symposium støttet av National Institute of Mental Health i USA. Den samme institusjonen (verdens største på området) fastslår da også i sin strategiske plan at psykiske lidelser må forstås og behandles som hjernesykdommer (3). Programerklæringene for de store nevrosatsningene tar tilsynelatende for gitt at mer hjerneforskning er nødvendig for å finne svar på våre dypeste spørsmål om oss selv som tenkende, følende og handlende vesener i en kompleks verden.

Det har riktignok etter hvert meldt seg flere kritikere av det som oppfattes som oversalg av hjerneforskningens resultater (noen har til og med lansert betegnelser som «neuromythology», «neurotrash», «neuromania» og «neuromadness» for å vise sin misnøye). Et nytt, vektig bidrag er boken Being Brains. Making the Cerebral Subject av vitenskapshistorikeren Fernando Vidal og sosialmedisineren og historikeren Francisco Ortega (4). Det bør kanskje understrekes at forfatterne ikke er motstandere av hjerneforskningen og dens resultater. De presiserer innledningsvis at - foruten verdien av kunnskap i seg selv - kan vel ingen være imot forskning som har som siktemål å forstå og behandle alvorlige hjernesykdommer, som for eksempel demens. Deres kritikk gjelder det de ser som ekstravagante påstander og ukritisk anvendelse av nevroforskningens resultater. Bokens tittel henspiller på tendensen til å redusere mennesket til hjernen (the cerebral subject), hvor forklaring på alle menneskelige fenomener forventes å finnes. Forfatterne hevder imidlertid at nevrobiologi ikke alltid er til hjelp, eller til og med relevant, for å forklare komplekse menneskelige fenomener - i motsetning til hvordan det ofte fremstilles i forskeres og organisasjoners begrunnelser for hvorfor det må mer forskning (og penger) til på akkurat deres felt.

Første del av boken - Genealogy of the Cerebral Subject - gir en historisk oversikt over synet på sammenhengen mellom hjerne og sinn, med kritikk av hvordan dagens forskere ofte setter likhetstegn mellom de to. Andre del - Disciplines of the Neuro - beskriver fremveksten siden tidlig på 1990-tallet av det Vidal og Ortega kaller et ekspanderende univers av nevrokultur. Tredje del er kalt Cerebralization of Psychological Distress og diskuterer bruken av nevrologiske termer for å forklare tilstander som schizofreni, autisme, depresjon, fedme og alkoholisme. Siste del av boken gir et kritisk blikk på hvordan nevrovitenskap brukes og ikke minst misbrukes i populærkulturen (Brains on Screen and Paper). 


\section{Begrepsforvirring om hjerne og sinn}

Utsagn som «du er din hjerne» kan kanskje virke uskyldige og til og med selvsagt, men innebærer egentlig en sammenslåing og forflating av to vesensforskjellige fenomener. Som uttrykt av den amerikanske psykologen Lisa Feldman Barrett (5): «Psychological states such as thoughts and feelings are real. Brain states are real. The problem is that the two are not real in the same way, creating the mind-brain correspondence problem.»

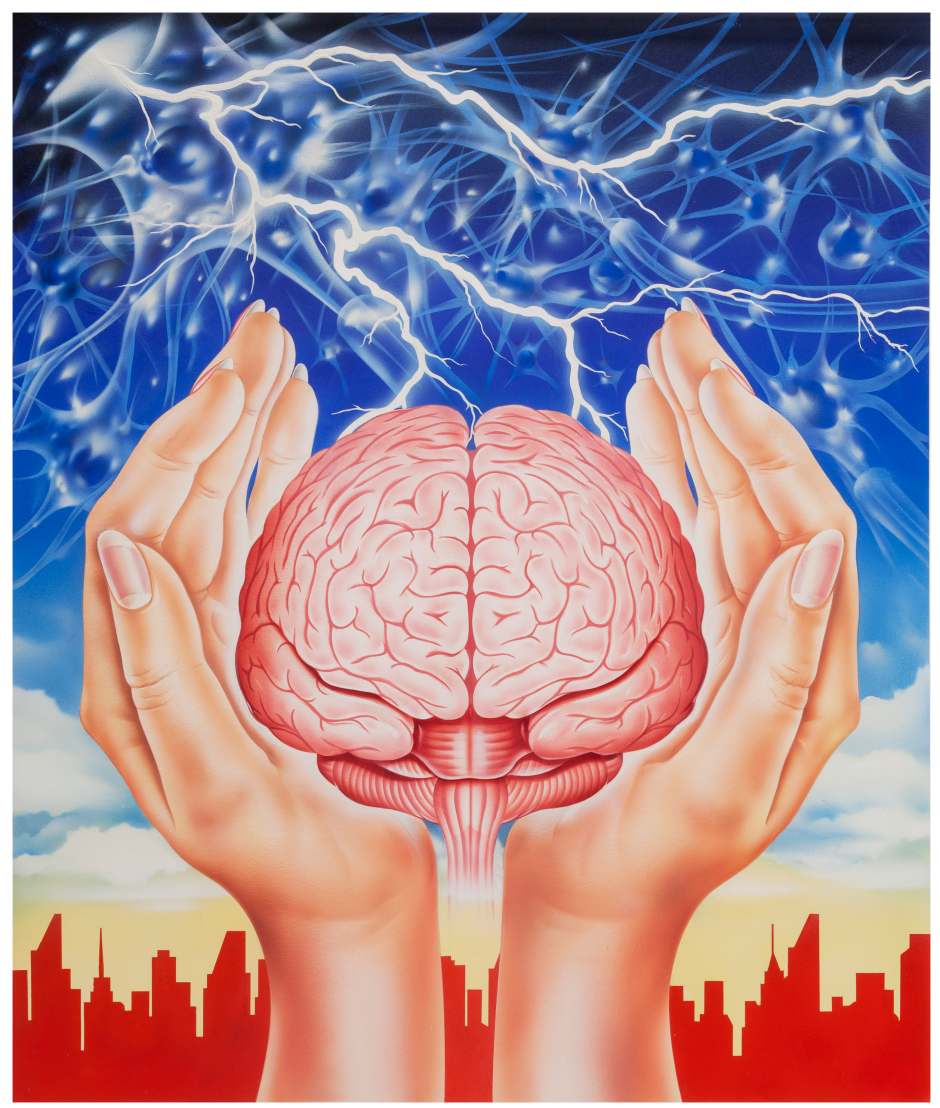

Illustrasjonsfoto: Science Photo Library/NTB scanpix

Sinnet (psyken) er heller ikke en enhet. Vi bruker ordet som en praktisk (men upresis) talemåte om noe som egentlig omfatter en rekke spesifikke menneskelige evner og deres bruk (føle, tenke, planlegge, ønske, huske, ville, mene, tro, snakke ...). Derfor vil ikke nevrovitenskap kunne fortelle oss hva sinnet er -ikke fordi det er for metafysisk unnvikende til å kunne undersøkes vitenskapelig, men fordi det ikke er noen slags enhet $\mathrm{i}$ det hele tatt, som presisert av filosofen Jonathan Trigg og psykologen Michael Kalish i artikkelen Explaining how the mind works: On the relation between cognitive science and philosophy (6).

Feldman Barrett påpeker videre at psykologer (men det gjelder også nevrobiologer) på leting etter årsakssammenhenger snakker om psykologiske fakta som om de var fysiske fakta som kan lokaliseres i hjernen. De tillegger da hjernen, eller deler av den, egenskaper som bare gir mening brukt om en person. Dette kaller nevrofysiologen Max Bennett og filosofen Peter Hacker en mereologisk feilslutning i boken Philosophical Foundations of Neuroscience (7). Med det menes å tillegge en del av en større helhet egenskaper som bare gir mening når de tilskrives helheten. Uten spesifikk hjerneaktivitet kan man ikke tenke, men det er jeg som tenker, ikke hjernen min. Her er to eksempler på mereologisk villfarelse fra ledende hjerneforskere: «The brain ... perceives and determines what is threatening ...» og "The brain is constantly making hypotheses that prepare for useful actions.»

Her er noen eksempler fra norske aviser på feilaktig begrepsbruk i formidling av hjerneforskning: «Det er klart du misliker urettferdighet. Men det er først nå vi kan konstatere at hjernen din er instinktivt helt enig med deg»; «Hjernen er streng, men rettferdig»; «Hvordan få det beste ut av hjernen» og «Skanner hjernen etter selvdisiplin». 
Mener forskerne at du og hjernen din er to uavhengige enheter? Er jeg som person og min hjerne uavhengige enheter som kommuniserer med hverandre? Gir det mening for meg å være enig (eller uenig) med hjernen min eller å snakke til hjernen? Er selvdisiplin en fysisk ting som kan lokaliseres i hjernen?

\section{Imperialistisk nevrokultur?}

Nevrokulturen, slik Vidal og Ortega beskriver den, omfatter nå en rekke nye fagfelt som alle har forstavelsen nevro: økonomi, jus, etikk, filosofi, antropologi, kultur, osv. Nevrososiologi er for eksempel definert som anvendelse av nevrobiologi i studiet av samfunnet. Det høres kanskje tilforlatelig ut, men ifølge Vidal og Ortega lover disse nye disiplinene å svare på spørsmål nevrovitenskapene i virkeligheten kan si lite om. Forstavelsen nevro tilkjennegir en hypotetisk lokalisering av psykologiske fenomener i hjernen, hvor vi kan lete etter «objektive» svar på våre dypeste spørsmål om bevissthet, læring, personlighet osv. Derved tillegges fagområder med nevro som forstavelse en ontologisk tyngde og forklaringsverdi som områdene angivelig mangler når de studeres med metoder fra samfunnsfag og humaniora, sier Vidal og Ortega.

Her kommer nevroforskningens urimelig høye prestisje inn og trumfer i mange tilfeller sunt vett og kritisk sans. Mange synes å godta at nerveceller i hjernen hvis aktivitet er assosiert tidsmessig med et psykologisk fenomen, er mer virkelige (objektive) enn personens (subjektive) opplevelse. Derfra sluttes at hvis vi kan finne substratet i hjernen for et fenomen og dokumentere det «objektivt» med nevrovitenskapelige metoder, slipper vi å forholde oss til menneskers mentale liv som subjektivt. Men det er misforstått: Smerte, for eksempel, er en opplevelse en person har og som i sin natur er subjektiv (å snakke om subjektiv smerteopplevelse er derfor i beste fall unødvendig, i verste fall villedende fordi det gir inntrykk av at det må finnes noe som heter objektiv smerte).

Bestemte hjerneprosesser er utvilsomt en nødvendig forutsetning for opplevelsen, men nervecellene og prosessene er ikke opplevelsen, og det hjelper personen lite å høre at smerten egentlig «sitter i hodet» (hvis det ikke dreier seg om hodepine). Forstår vi motivasjon, glede og sorg bedre ved å vite at dopamin (blant tallrike andre signalstoffer) spiller en rolle for disse fenomenene? Selv om amygdala er en av de strukturene i hjernen som mest konsistent viser endret aktivitet assosiert med sterke følelser, er det misforstått å snakke om at følelsene sitter i amygdala eller å tro at ordene amygdala og følelser kan brukes som synonymer. Det er like lite fruktbart som å lete etter meningen med begrepet transport ved å ta fra hverandre en bil i sine enkeltdeler og unders $\varnothing$ ke dem i detalj.

\section{Hjerneskanning og menneskesinnet}

Nevrokulturen er i stor grad basert på resultater oppnådd med hjerneskanning, spesielt funksjonell magnetresonanstomografi (fMR). Det er en enorm og stadig voksende litteratur basert på fMR anvendt i forbindelse med ulike mentale aktiviteter. Det har etter hvert vist seg at det er betydelige feilkilder forbundet med metoden, med derav følgende rapportering av store mengder falskt positive og falskt negative funn. En av de mest åpenbare svakhetene er lav statistisk styrke i en stor andel av publiserte artikler. Vidal og Ortega diskuterer også bruken av fMR i studiet av sammenhengen mellom hjerne og sinn. Brukt i de rette hender og tolket med forstand kan hjerneskanning utvilsomt bidra til å belyse alt fra hjerneprosesser som ligger til grunn for observerbar atferd til formulering av testbare hypoteser. Men selv med den mest solide metodikk gjenstår spørsmålet om hva hjerneskanning egentlig kan si noe om, hevder Vidal og Ortega. 


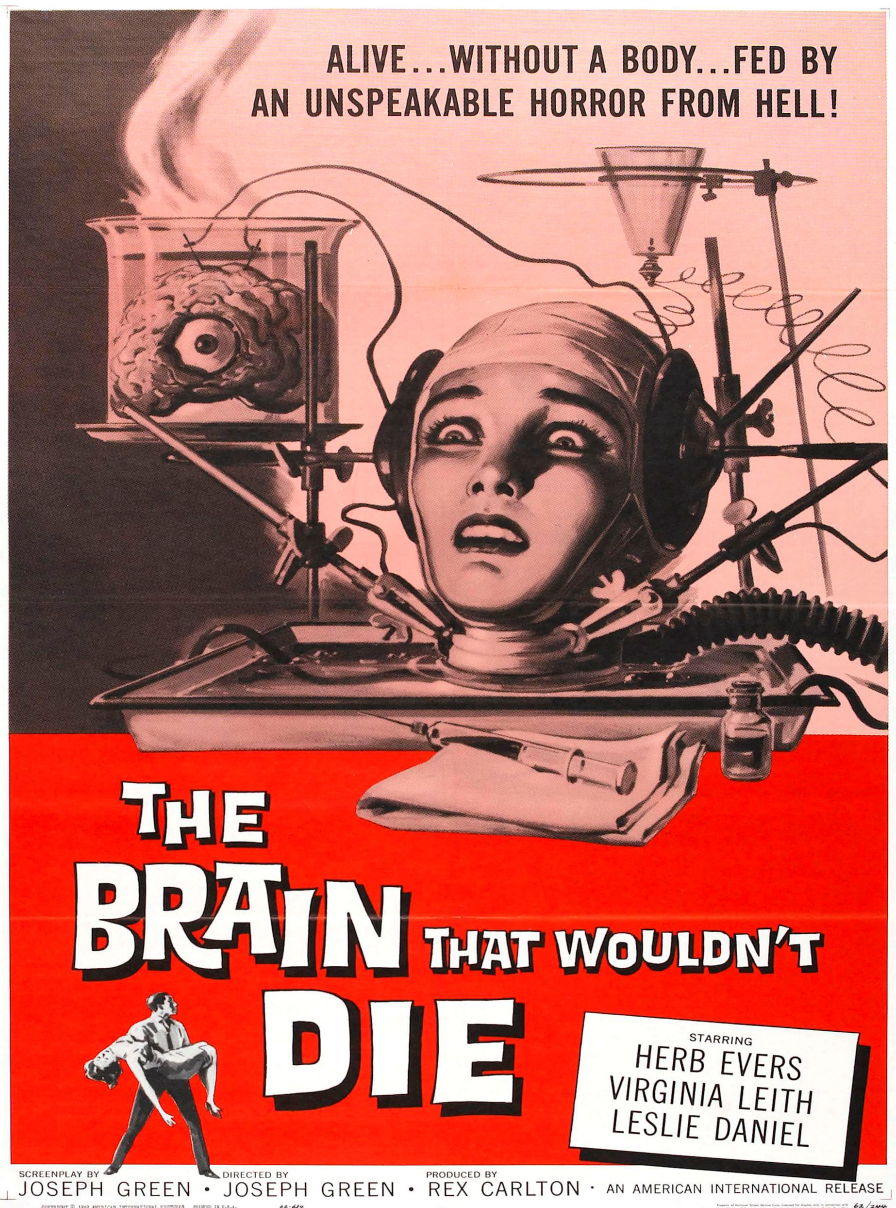

The Brain That Wouldn't Die, en filmplakat fra 1962. Illustrasjon: Global Panorama/Flickr. Tilgjengelig under CC BY-SA 2.o Lisens

De påpeker at det grunnleggende problemet med de nye nevrofagene (som nevroetikk, nevrojus, nevrokultur osv.) er om fMR i det hele tatt kan gi svar på feltenes sentrale spørsmål. I boken Brain Imaging. What it Can (and Cannot) Tell Us About Consciousness (8) foretar biofysikeren Robert G. Shulman en kritisk gjennomgang av dette spørsmålet. Han er en av pionerene innen bruk av MR og arbeidet først innen fysikk og biokjemi, men gikk så etter hvert over til hjerneskanning. Han ble da klar over at når metoden går fra å brukes til å undersøke partiklers energi og molekylers struktur til å finne svar på hvordan vi kan huske eller hva som får oss til å gråte, må forskerne forholde seg til metafysiske fenomener som sinn og bevissthet. Da rekker ikke den erkjennelsesteorien som brukes når man analyserer fysiske forhold. Shulman påpeker at forventningene til hjerneskanningens forklaringsverdi blir hausset opp ved at superbe metoder og verdifulle eksperimentelle funn blandes sammen med uholdbare tolkninger og påstander.

\section{Keiserens nye klær}

Vidal og Ortega er altså kritiske til hvor mye nevroforskningens metoder egentlig kan fortelle oss om sammenhengen mellom hjernen og psykologiske fenomener. Ofte fremstilles trivialiteter som dyp innsikt og erkjennelsesmessige gjennombrudd. Tallrike artikler, bøker og nettsider der man lanserer metoder for selvhjelp og læring, påberoper seg å bygge på nevroforskning. Men de fleste gjør egentlig ikke mer enn å sammenstille informasjon om atferd med trivielle nevrovitenskapelige data. Noen nøyer seg med å slå fast at de psykologiske fenomenene har korrelater i hjernen og derfor forstår vi dem (selvsagt) bedre. «Kreativ markedsføring i forledende innpakning», sier Vidal og Ortega. «Hjernebasert læring» (brain-based learning) finnes for eksempel som uimotståelig «vitenskapelig» salgsargument i en rekke kommersielle læringsprogrammer. Men dette er jo virkelig keiserens nye klær: Det er vel i dag knapt noen som tror at vi kan lære uten en fungerende hjerne. Det burde derfor være verken merkelig eller overraskende at atferdsforskjeller 
mellom mennesker er assosiert med forskjeller i hjernen. Ville det ikke vært merkeligere hvis forskjeller i atferd ikke hadde et korrelat i hjernen? At for eksempel hjernen til en person med autisme har noen forskjeller (påvist med hjerneskanning) fra hjernen til en person uten autisme, er derfor det man ville forvente. Det gir i seg selv ingen dypere innsikt. Effekter av meditasjon, empatitrening eller kognitiv terapi blir heller ikke mer reelle fordi de blir vist å ha korrelat i hjernen.

Filosofen Mary Midgley påpeker i boken Are you an illusion? at vi ikke trengte å vente på oppdagelsen av speilnevroner i hjernen for å vite at mennesker kan gjenkjenne hverandres følelser direkte (en annen sak er at det er tvilsomt om speilnevroner overhodet spiller noen rolle for gjenkjennelse av følelser) (9). Hun kritiserer også det hun mener er en utbredt forestilling blant nevroforskere om at direkte uttrykk for våre egne opplevelser er verdiløse inntil de har fått en vitenskapelig autorisering. Vi kan ikke akseptere at du har «virkelige» smerter før vi har skannet hjernen din, eller at du snakker sant før du er hjerneskannet.

\section{Integrasjon av ulike forklaringsnivåer}

Resultater fra hjerneskanning blir mer enn trivialiteter først når man kan etablere sammenheng mellom hjerneforskjeller og psykologiske teorier, som jo er mye nærmere til å forklare atferd enn hjerneforskning. Dette krever at det bygges bro mellom nevroforskning og kognitiv psykologi, det vil si mellom ulike forklaringsnivåer. Et imponerende eksempel på slik brobygging skjer i boken The organisation of mind av Tim Shallice og Richard Cooper (10). De hevder at en dypere forståelse av mentale prosesser forhindres av at forskere innen nevrovitenskapene ofte ignorerer det kognitive (psykologiske) forklaringsnivået. En slik reduksjonistisk tilnærming der data fra nevrovitenskapene alene forklarer mentale prosesser, er dessverre fortsatt utbredt.

LITTERATUR:

1. Galin D. The blind wise men and the elephant of consciousness. Conscious Cogn 1992; 1: 8 - 11. [CrossRef]

2. Lee FS, Heimer H, Giedd JN et al. Mental health. Adolescent mental health-opportunity and obligation. Science 2014; 346:547 - 9. [PubMed][CrossRef]

3. National Institute of Mental Health. NIMH Strategic Plan for Research. https://www.nimh.nih.gov/about/strategic-planning-reports/introduction.shtml (18.9.2018).

4. Vidal F, Ortega F. Being brains. Making cerebral subjects. New York, NY: Fordham University Press, 2017.

5. Barrett LF. The future of psychology: Connecting mind to brain. Perspect Psychol Sci 2009; 4:326 - 39. [PubMed][CrossRef]

6. Trigg J, Kalish M. Explaining how the mind works: on the relation between cognitive science and philosophy. Top Cogn Sci 2011;3:399 - 424. [PubMed][CrossRef]

7. Bennett MR, Hacker PMS. The philosophical foundations of neuroscience. Oxford: Blackwell Publishing, 2003.

8. Shulman RG. Brain imaging. What it can (and cannot) tell us about consciousness. Oxford: Oxford University Press, 2013.

9. Midgley M. Are you an illusion? Durham: Acumen, 2014.

10. Shallice T, Cooper RP. The organisation of mind. Oxford: Oxford University Press, 2011.

Publisert: 10. desember 2018. Tidsskr Nor Legeforen. DOI: 10.4045/tidsskr.18.0707

Mottatt 10.9.2018, første revisjon innsendt 24.9.2018, godkjent 25.9.2018.

(C) Tidsskrift for Den norske legeforening 2020. Lastet ned fra tidsskriftet.no 